\title{
CUESTIONES OFTALMOLÓGICAS EN LA OBRA DE FEIJOO (II)
}

\author{
SAMPEDRO A ${ }^{1}$, BARBÓN-GARCÍA JJ ${ }^{1}$
}

El padre Feijoo nos recuerda cómo el remedio para muchos padecimientos oculares está en la Óptica: «muchas de las lesiones de los ojos piden para su conocimiento, y curación la pericia en otra facultad distinta de la Medicina, que es una de las Matemáticas, llamada Optica. Por esto en otras Naciones, que abundan de Artífices para todo, tienen Médicos especiales para las enfermedades de los ojos, que por eso se llaman Oculistas; a ellos remiten los Médicos comunes a cualquiera que los consulta sobre afectos oculares; y cuando no lo hacen, suelen caer en notables errores». En España la oftalmología estaba dentro de la Cirugía General y no surgen cursos de formación específicos hasta el s. XIX, aunque a mitad del siglo XVIII el Gobierno había paliado en parte esta situación al disponer que del Colegio de Cirugía de Cádiz salieran algunos colegiales a Paris para estudiar la especialidad, y a finales de siglo ya se contaba con textos en castellano.

Las abundantes supersticiones extendidas en la época, como el mal de ojo, son duramente atacadas y desmontadas desde la razón. «La fascinación, o mal de ojos... Entre todas las observaciones vanas entiendo que esta es la más común, y también la más antigua». Feijoo repasa la opinión de algunos autores desde la antigüedad y cómo queda fuera de todas las reglas de la medicina la creencia en que se pueda provocar la enfermedad con la mirada: «Es claro en buena Física, que nada de esto puede suceder. La vista no es activa, sino dentro del propio órgano. Los ojos reciben las especies de los objetos; pero nada envían a ellos». (Teatro Crítico: Discurso 5, tomo V).

La charlatanería médica es analizada con detenimiento en respuesta a cierto Italiano advenedizo que hacía algunas curas admirables en una Ciudad de España (Cartas Eruditas, Carta 4, Tomo IV). La situación médica en el siglo XVIII parece bastante caótica con charlatanes itinerantes que vendían curaciones de enfermedades incurables o simulaban milagros falsos y con la presencia de extranjeros que recorrían España para adquirir la destreza en cirugías que apenas conocían: «Y lo más admirable, que hay en esto, es la impunidad con que estos pícaros engañan las gentes. De muchos que he visto, no sé que haya sido castigado alguno». La credulidad e ignorancia populares eran un campo abonado para todas estas prácticas: «son infinitos los necios, que

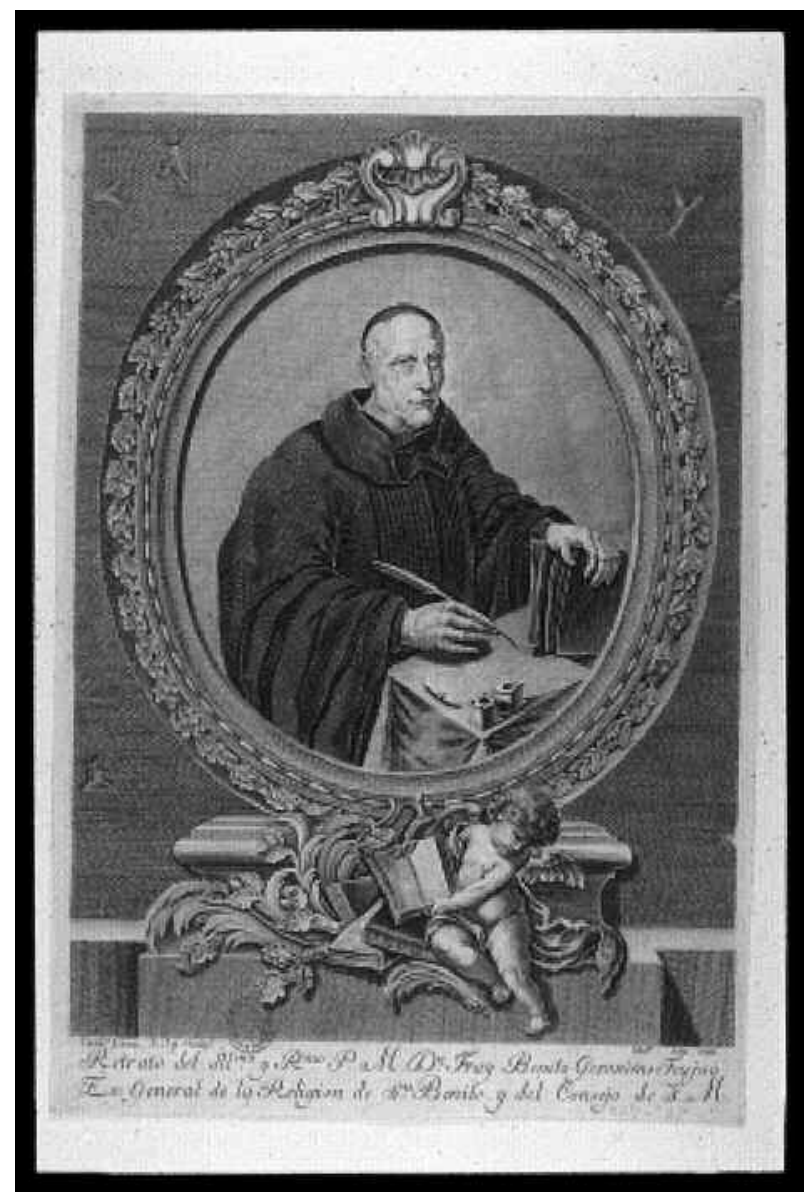

BJ Feijoo.

\footnotetext{
${ }^{1}$ Licenciado en Oftalmología. Servicio de Oftalmología Hospital San Agustín de Avilés. Asturias. España.

E-mail: jjbarbon@telecable.es
} 


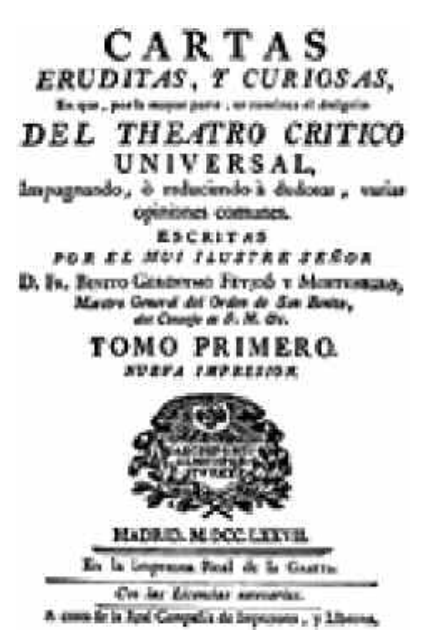

Cartas eruditas.

creen a estos Charlatanes, sin que los malos sucesos de los unos sirvan de escarmiento para los otros». En Europa los oculistas eran especialistas más cualificados, a diferencia de España, donde se mantenían como empíricos carentes de cualquier formación teórica: «Es cierto, que en las Naciones hay, aunque muy pocos, algunos excelentes Profesores de este Arte, que en efecto pide grande estudio, y singular destreza. La Nación Anglicana, sobre todo, los tiene, y ha tenido nobilísimos. ¿Pero viene alguno de estos diestros Operadores a España? En ningún modo».

Sobre la clase medica y los oculistas en particular asevera sin piedad: «todos los Curanderos, que vienen por acá, juzgo, que los más bien admitidos son los que llaman Oculistas. Y sin embargo, acaso éstos son los que más daño hacen», e insiste en la denuncia de los supuestos oculistas que venían a España a adquirir una cierta experiencia para regresar después a ejercer en sus países «los que vienen por acá, son unos malos aprendices, que si algún día llegan a mejorar la vista a alguno, es después que la han destruido a trescientos». Al respecto nos cuenta la confidencia que le hizo el médico Don Juan de Elgar: «... me refirió, que estando en la de Bayona de Francia, pasó por allí un Paisano suyo, que le dijo venía a ejercer el oficio de Oculista en España. Conocíale D. Juan de Elgar; y sabiendo que estaba muy poco instruído aún en los rudimentos del Arte, le preguntó: ¿Cómo con tan pocos principios se atrevía a practicarla? A lo que muy serenamente le respondió el Oculista novicio: Monsieur, es así que yo sé muy poco; pero dando vuelta dos, o tres años por las Provincias de España, iré adquiriendo algún conocimiento experimental; de modo, que estaré tanto cuanto, hábil cuando me restituya a Francia. Este conocimiento experimental ¿cómo se había de adquirir sino haciendo ciegos a muchos, antes de poder curar alguno?».

El padre Feijoo también recoge la noticia de prensa en la que se desenmascaraba a uno de los grandes charlatanes oculistas de aquel tiempo, que recorría Europa en lujosos carruajes y se hacía llamar el Caballero Taylor: «El Profesor de Anatomía, y Cirugía, los Inspectores de Medicina, y los Médicos de la Ciudad de Amsterdam advierten al Público, que estando informados exactamente de cuanto se ha publicado en las Gacetas de Holanda, y Francia sobre las maravillosas operaciones hechas por el nombrado Taylor, Oculista, han descubierto, que la mayor parte es falso; y que sus curaciones han sido tan inútiles, y fatales a los pacientes, como lo fueron las que hizo quince años há en esta Ciudad». Y previene: «Ojo alerta Españoles míos, y cuenta cada uno con sus ojos. Si estos bribones Charlatanes son capaces de engañar en Holanda, y Francia, donde hay tanta copia de hombres hábiles en todas Facultades, especialmente en las operativas; ¡con cuánta mayor facilidad podrán engañar en España!».

En otra de sus Cartas (Carta XVI, Tomo III) responde a una consulta por si hallaba algún remedio a la lesión ocular de cierto caballero, por «estar mirando al sol de hito en hito largo rato» y que juzga, de acuerdo a los Doctores que lo habían examinado previamente «de muy difícil y acaso imposible curación» por asentar en la retina. La explicación de la afectación del área visual resulta muy acertada salvo por el error anatómico de situar el nervio óptico en el lugar que correspondería a la mácula y, así esta lesión retiniana estaría «... no en toda ella sí sólo en su parte central, o en el medio, donde termina el nervio óptico, que es el sitio en que hicieron impresión los rayos del Sol; digo la impresión más viva, y eficaz; lo que es general a los rayos visuales de cualquier objeto que vienen ... por aquella línea, que, saliendo del objeto, se considera encaminarse por el centro, o medio de los tres humores del ojo perpendicular a ellos, y se termina en el centro de la retina». Al final reconoce sus limitaciones en la materia $\mathrm{y}$, muy juiciosamente recomienda consultar a «un Oculista Extranjero muy perito en su arte. Y si salió ya de Santiago, sería para la de Lisboa, de donde me dicen está llamado».

Los remedios milagrosos fueron duramente atacados como hace en esta descripción sobre la capa- 
cidad del globo ocular para restituir su volumen tras punción (Teatro Crítico, discurso 14, Tomo 2), «en las observaciones de Rhedi consta, que rompidos los ojos con aguja, o lanceta, sin aplicación de algún remedio, se recobra la vista por puro beneficio de la naturaleza en menos de 24 horas. Así lo experimentó el citado Autor en varias especies de aves. Por tanto se debe creer, que el zumo de la Celidonia, y otras drogas, que como secreto venden algunos para este efecto, es puro embuste de charlatanes, que sabiendo que la curación se deberá a la naturaleza, sin socorrerla con algún auxilio, venden como remedio lo que no hace daño, ni provecho».

\section{BIBLIOGRAFÍA}

1. Fernández González AR. Benito Jerónimo Feijoo. Teatro Crítico Universal. IV ed. Madrid: Ed. Cátedra, 1989.

2. Telenti A. Aspectos médicos en la obra del maestro B. J. Feijoo. Oviedo: Publicaciones del IDEA, 1969.

3. Marañón G. Las ideas biológicas del P Feijoo. II ed. Madrid: Espasa Calpe, 1941.

4. Biblioteca feijoniana del Proyecto Filosofía en español. www.filosofia.org/bjf/

5. Hernández Benito E. Oftalmología española de la ilustración, Siglo XVIII. In Cotallo JL, Hernández E, Munoa JL, Leoz C. Historia de la oftalmología española. 69 Ponencia de la Sociedad Española de Oftalmología. Madrid: Sociedad Española de Oftalmología; 1993; 113-158. 